\title{
COMMENTARY
}

\section{Translating evidence into practice: how good is good enough?}

\author{
Colin R. Cooke MD MSc \\ Clinical Lecturer, Division of Pulmonary \& Critical Care Medicine, University of Michigan, Ann Arbor, MI, USA and Clinical Scholar, Robert Wood \\ Johnson Clinical Scholar's Program, University of Michigan, Ann Arbor, MI, USA \\ doi:10.1111/j.1365-2753.2009.01346.x
}

The birth of the evidence-based medicine (EBM) movement in the early 1990s generated a greater interest in measuring the extent to which scientific knowledge was appropriately applied to therapeutic decisions. Investigators sought to challenge the widespread belief that only a minority of treatments provided to patients were based upon the best available scientific evidence. In 1995 Ellis and colleagues, many of whom were among the greatest champions of the evidence-based movement, published one of the earliest attempts to quantify the diffusion of evidence-based treatment into everyday practice [1]. In their study, investigators identified the primary diagnosis, and the therapy used to treat each diagnosis, for 109 patients admitted over a 1-month period to the inpatient ward at a UK hospital. Through an extensive literature search, the investigators determined that the medical literature supported $82 \%$ of the diagnosis-therapy pairs and $52 \%$ were supported by data from randomized controlled trials. Similar studies quantifying adherence to 'best evidence' built upon the quality assurance work of Donabedian [2] and helped lay the foundation of modern day research that examines the process of moving empiric data from research to clinical practice - knowledge translation $[3,4]$ - and forms the basis of popular quality improvement initiatives around the world.

Modern day knowledge translation research and quality improvement initiatives serve as excellent examples of the current importance given to measuring adherence to the best scientific evidence. In 1999 the US Congress formed the Agency of Health Research and Quality (AHRQ) and tasked it, among other things, to "promote health care quality improvement by conducting and supporting the synthesis and dissemination of available scientific evidence for use by patients, consumers, practitioners, providers, purchasers, policy makers, and educators' [5]. In 2010 it is estimated that over $\$ 370$ million US dollars will be appropriated to the AHRQ towards achieving this goal [6]. While considerable, this amount represents only $1 \%$ of the total budget of the National Institutes of Health [7]. Despite greater interest in EBM and greater funding to study EBM penetration, numerous studies involving tens of thousands of patients illustrate that a significant proportion of eligible patients in the USA and the UK do not receive therapies known to improve outcomes [8-12]. This fact is widely accepted and arguably justifies a need for even greater research spending aimed at using EBM to improve patient outcomes [13].

It is within this context that we consider the current study conducted by Ayre and Walters [14]. In their analysis, the authors seek to repeat a study similar in design to that conducted by Ellis hypothesizing that the rapid expansion of published evidence since 1995 comes with a concomitant expansion in the appropriate use of EBM at the bedside. A total of 150 diagnosis-therapy pairs from 102 patients were identified over a 1-month period from an inpatient service in the UK. A literature search identified if the therapy for each pair was supported by evidence. The authors determined that only $52 \%$ of diagnosis-therapy pairs were supported by systematic reviews or randomized controlled trials, the two highest levels of evidence considered. An additional $32 \%$ of pairs were based upon non-experimental evidence. When these numbers are compared with Ellis, and other similar studies, there has been no real change in the proportion of medical inpatients receiving evidence-based therapies.

The study has a number of limitations that are worth mentioning. First, each patient's diagnosis was retrospectively abstracted from the medical record by a single individual. No definitions or confirmations of the diagnoses are provided, preventing the reader from assessing the validity of a diagnostic label. Second, no attempt was made to exclude patients with a given diagnosis who were ineligible for the highest level of evidence because of contraindications. For example, anticoagulation is contraindicated in patients with a deep venous thrombosis who have an active gastrointestinal hemorrhage. These first two limitations could dramatically impact the proportion of diagnosis-therapy pairs that are evidence-based. Third, no data is provided that would help the reader assess the generalizability of this study, including patient demographics, and make-up of the inpatient medical team. It is unlikely that results from 150 patients from a single centre generalize to other patients/centres. Moreover, no information is provided about the whether institution in which patients were treated engages in activities known to improve EBM adherence such as educational outreach, pay for performance, behavioral audit and feedback, and computerized reminders $[12,15]$. Fourth, the authors provide no estimate of precision (95\% confidence intervals) for their proportions. Given the small numbers in the study the estimates are likely to have only moderate precision. In general, the study would be greatly strengthened had the authors taken a more evidence-based approach to the design of the study and reporting of the results $[16,17]$.

So what can we learn from this limited study that re-illustrates the well known fact: clinicians mostly adhere to evidence-based therapies but not all of the time? First, the absence of $100 \%$ adherence to EBM at the bedside persists despite the rapid increase in published evidence, greater international focus on quality and safety, and a better understanding of how to bridge the gap 
between what we know and how we practice. This observation, while not unexpected, reinforces prior and ongoing work by others. Second, this study illustrates the need to move beyond just describing rates of EBM use and focus on characterizing the causes of non-adherence. Understanding why evidence is not adopted characterizes much of the research conducted by knowledge translation investigators and investigators already know a great deal about the barriers to adoption of evidence $[4,18]$. Efforts to improve adherence to evidence have been successful in numerous contexts $[9,12]$, and more attention to this goal is certainly warranted.

Finally, novel hypotheses explaining the persistence in nonperfect EBM adherence must be considered. It may very well be that a goal of $100 \%$ adherence to evidence-based therapies does not represent best clinical practice. Exceptions exist to every rule, and the duty of the physician is to individual patients. While traditional efforts to improve the care of patients focus on altering provider and system-level behavior to conform to the EBM paradigm [4], an alternative approach would be to consider re-shaping the EBM paradigm to incorporate routine and appropriate aspects of care not rooted in empiric observation. Some have proposed this approach as casuistic alternative to EBM [19]. One of the reasons adherence to EBM may not be $100 \%$ is because physicians may continue to rely upon non-evidentiary warrants for therapeutic decisions. In other words, one could hypothesize that EBM has failed to change physician's use of experiential evidence, pathophysiologic rationale, patient goals and values, and other system factors when making therapeutic decisions [19]. This hypothesis is supported by the multiple diagnosis-therapy pairs listed as category 3 (convincing non-experimental evidence) or 4 (no contrary evidence) where providers likely relied upon experience and patient preference. For example, use of non-steroidal anti-inflammatory drugs for musculoskeletal chest pain may not have been demonstrated in a randomized controlled trial to provide benefit over placebo, but when a patient has an excellent individual response to the therapy, it is hard to argue to withhold it. Similarly, while nebulized delivery of inhaled medication does not appear to have advantages compared with using a spacer with a metered dose inhaler, withholding a nebulizer from a patient in respiratory distress who feels that she gets more rapid relief from that delivery system does not seem to practicing patient-centred medicine.

In sum, Ayer and Walters report [14], while suffering from many of the same limitations as studies by Ellis and others, suggests that the nature of the practice of medicine has changed very little over the last decade, a decade dominated by the EBM movement. The author's appear a bit chagrined by this fact, and certainly more can be done to ensure that clinicians take the knowledge gained from clinical research into account when caring for patients. But perhaps they should not consider the results a failing of EBM. Instead, it may be that optimal practice of medicine should rely on empirical evidence only much of the time, and appropriately base some decisions on more compelling and non-evidentiary reasons.

\section{Acknowledgements}

The author would like to thank Mark R. Tonelli for his thoughtful comments on an earlier draft of this commentary.

\section{References}

1. Ellis, J., Mulligan, I., Rowe, J. \& Sackett, D. L. (1995) Inpatient general medicine is evidence based. A-Team, Nuffield Department of Clinical Medicine. Lancet, 346 (8972), 407-410.

2. Donabedian, A. (1966) Evaluating the quality of medical care. Milbank Memoires of the Fund Quarterly, 44 (3) (Suppl), 166206.

3. Graham, I. D., Logan, J., Harrison, M. B., Straus, S. E., Tetroe, J., Caswell, W. \& Robinson, N. (2006) Lost in knowledge translation: time for a map? Journal of Continuing Education in the Health Professions, 26 (1), 13-24.

4. Straus, S. E., Tetroe, J. \& Graham, I. (2009) Defining knowledge translation. Canadian Medical Association Journal, 181 (3-4), 165168.

5. Healthcare Research and Quality Act of 1999 (1999) HRQA, PL 106-129; US Congress.

6. Agency for Healthcare Research and Quality (2009) Budget estimates for appropriations committees, fiscal year 2010. Available at: http://www.ahrq.gov/about/cj2010/cjweb10sum.htm (last accessed 21 September 2009).

7. National Institutes of Health (2009) National Institutes of Health summary of the FY 2010 president's budget. Available at: http://officeofbudget.od.nih.gov/pdfs/FY10/Tabular\%20Data.pdf (last accessed 30 September 2009).

8. Marciniak, T. A., Ellerbeck, E. F., Radford, M. J., Kresowik, T. F., Gold, J. A., Krumholz, H. M., Kiefe, C. I., Allman, R. M., Vogel, R. A. \& Jencks, S. F. (1998) Improving the quality of care for Medicare patients with acute myocardial infarction: results from the Cooperative Cardiovascular Project. Journal of the American Medical Association, 279 (17), 13511357.

9. Jencks, S. F., Huff, E. D. \& Cuerdon, T. (2003) Change in the quality of care delivered to Medicare beneficiaries, 1998-1999-20002001. Journal of the American Medical Association, 289 (3), 305 312.

10. McGlynn, E. A., Asch, S. M., Adams, J., Keesey, J., Hicks, J., DeCristofaro, A. \& Kerr, E. A. (2003) The quality of health care delivered to adults in the United States. New England Journal of Medicine, 348 (26), 2635-2645.

11. Campbell, S., Reeves, D., Kontopantelis, E., Middleton, E., Sibbald, B. \& Roland, M. (2007) Quality of primary care in England with the introduction of pay for performance. New England Journal of Medicine, 357 (2), 181-190.

12. Campbell, S. M., Reeves, D., Kontopantelis, E., Sibbald, B. \& Roland, M. (2009) Effects of pay for performance on the quality of primary care in England. New England Journal of Medicine, 361 (4), 368-378.

13. Institute of Medicine (2001) Crossing the Quality Chasm: A New Health System for the 21st Century. Washington, DC: National Academy Press.

14. Ayre, S. \& Walters, G. (2009) Are therapeutic decisions made on the medical admissions unit any more evidence-based the they used to be? Journal of Evaluation in Clinical Practice, 15, 11801186.

15. Grimshaw, J., Eccles, M., Thomas, R., MacLennan, G., Ramsay, C., Fraser, C. \& Vale, L. (2006) Toward evidence-based quality improvement. Evidence (and its limitations) of the effectiveness of guideline dissemination and implementation strategies 1966-1998. Journal of General Internal Medicine, 21 (Suppl 2), S14 S20.

16. Hulley, S. B. (2007) Designing Clinical Research. Philadelphia, PA: Wolters Kluwer Health/Lippincott Williams \& Wilkins.

17. Vandenbroucke, J. P., von Elm, E., Altman, D. G., Gotzsche, P. C., 
Mulrow, C. D., Pocock, S. J., Poole, C., Schlesselman, J. J. \& Egger, M. (2007) Strengthening the Reporting of Observational Studies in Epidemiology (STROBE): explanation and elaboration. Annals of Internal Medicine, 147 (8), W163-W194.

18. Davis, D., Evans, M., Jadad, A., et al. (2003) The case for knowledge translation: shortening the journey from evidence to effect. British Medical Journal, 327 (7405), 33-35.

19. Tonelli, M. R. (2006) Integrating evidence into clinical practice: an alternative to evidence-based approaches. Journal of Evaluation in Clinical Practice, 12 (3), 248-256. 